\title{
Lassa Fever: Current Treatment and Prospects of an Effective
}

\section{Vaccine}

\author{
Anusiem $\mathrm{CA}^{1}{ }^{*}$, Amechi NS ${ }^{2}$, Anusiem $\mathrm{AC}^{3}$ and Ugwunna NC ${ }^{4}$ \\ ${ }^{1}$ Department of Pharmacology and Therapeutics, University of Nigeria Nsukka, \\ Nigeria \\ ${ }^{2}$ Department of Pharmacology and Therapeutics, Ebonyi State University, Nigeria \\ ${ }^{3}$ Nursing Services division, University of Nigeria Teaching Hospital, Enugu Nigeria \\ ${ }^{4}$ Department of Community Medicine, University of Nigeria, Enugu Nigeria
}

\section{Review Article}

Volume 3 Issue 1

Received Date: March 12, 2019

Published Date: April 03, 2019

DOI: $10.23880 /$ vij- 16000207

*Corresponding author: Chikere A Anusiem, Department of Pharmacology and Therapeutics, college of Medicine, University of Nigeria Teaching hospital, Enugu, Nigeria, Email: chikere.anusiem@unn.edu.ng

\section{Abstract}

Lassa fever (LF) has been a topical viral haemorrhagic fever with recurrent outbreaks in parts of West Africa where it has been endemic for some decades. It is a zoonotic disease with fatality of about $1 \%$ in the on-going outbreak in Nigeria. LF is responsible for the death of about 5,000 people annually, but till date has no preventive vaccine. In this paper we presented a brief virology of the causative agent of LF and reviewed the clinical presentation, requisite precautionary measures, diagnosis and current treatment of the virus infection. In addition the frontline vaccine candidates and prospects of having a prophylactic vaccine for Lassa fever are highlighted.

Keywords: Lassa Fever; Treatment; Vaccine; Ribavirin; Viral Hemorrhagic Fever

Abbreviations: LF: Lassa fever; LASV: Lassa Fever Virus; GPC: Glycoprotein Precursor Complex; WHO: World Health Organization.

\section{Introduction}

Lassa fever (LF) is one of the viral haemorrhagic fevers [1]. Human beings acquire the infection from contact with the urine or excreta of the carrier rat called Mastomys natalensis [2,3]. The causative micro-organism, Lassa fever virus (LASV), was isolated in 1969 in the town of Lassa in Borno State of Nigeria although the illness was first described in the 1950s [4-6]. LF has an incubation period of 5-21 days and the duration of the illness is typically 2-21 days. The disease is endemic in West African nations particularly Sierra Leone, Liberia, Guinea, Benin Republic, Nigeria, Ghana, and Mali [7]. Nigeria's latest outbreak has resulted in more than 130 deaths within 9 months. However cases of LF have been seen in the USA and some other non-African countries presumably due to international travels to and fro endemic countries and in the search of efficacious treatment [8-10]. Approximately 100,000 to 500,000 LF cases occur annually with about 5000 deaths annually [4,11]. Only about $20 \%$ of persons infected with LASV actually develop clinical LF whereas about $80 \%$ of infected people remain asymptomatic [12].

LASV itself is an emerging virus with epidemic potential [13] and has been listed among the pathogens that require Biosafety level 4-equivalent containment. It is an arenavirus and belongs to the Arenaviridae virus family. It is an enveloped virus with pleomorphic virions having filamentous helical nucleocapsids. It has 


\section{Virology \& Immunology Journal}

ambisense genomic configuration with bisegmented negative sense single stranded RNA genome $[14,15]$. LASV is one of the most clinically significant viruses among the members of the arenaviridae virus family [16]. It has a surface molecule named Glycoprotein Precursor Complex (GPC) which mediates both the binding of the virus to host cells and viral entry into host cells. GPC is a key element in the vaccinology of LF [17].

The primary target cells of LASV on entry into the human body are the antigen presenting cells (macrophages and dendritic cells). The state of activation of the antigen presenting cells (APCs) on challenge with LASV is an early determinant of how the infection will evolve. Typically in LASV infection, APCs tend to express ineffective antigen processing and presentation activity as a result of failure to undergo activation and maturation $[14,18]$.

Type 1-IFN response is a key mediator of protection in LF infection. Up-regulation of IFN $\alpha$ signaling soon after LASV infection is a determinant of good outcome after exposure to LASV. Apparently where LASV is able to alter or suppress effective type 1 IFN response would lead to increased LASV replication and impaired innate and adaptive immune responses leading to poor viral challenge and progression of the disease process to a severe form and possibly to a fatal outcome [19].

The natural host of LASV is a small rodent named Mastomys natalensis, also called the multimammate rat. The rat is a small soft furred rodent commonly found in West Africa [20]. The virus is transmitted to man by direct contact with the excreta or urine of the carrier rat $[7,13]$.

\section{Presenting Features}

Lassa fever in its early stage presents insidiously with symptoms that are usually observed in influenza and some common tropical fevers such as malaria and typhoid fever [21]. In the majority of cases LF manifests as a mild disease $[3,13]$. Headaches, fever, tiredness, myalgias, are the initial common symptoms corresponding to early viraemia. As the illness gets more serious diarrhea, vomiting of blood, passage of bloody stools, abdominal pain, and skin rash develop, pointing to the onset of gastrointestinal bleeding. Such patients may additionally bleed from mucous membranes of the body, gums, eyes, and nostrils [22-24]. Other clinical features are generalized oedema, deafness, respiratory distress and hypotension. Symptoms referable to the neuronal system include: tremors, deafness, and encephalitis $[3,25]$. In fatal cases, cardiovascular shock and multi-organ failure may precede death.

\section{Diagnosis}

The World Health Organization (WHO) has provided diagnostic criteria for the diagnosis of LF. Essentially where an individual is suspected of having LF, treatment with antimalarials and antibiotics is first offered. If fever persists 48-72 hours after treatment, specific laboratory tests for LF will then be carried out to confirm or rule out a diagnosis of LF.

The laboratory diagnosis is made by ELISA test for LASV antigen or IgM immunoglobin [23,26,27]. The gold standard confirmatory test is by Reverse transcription polymerase chain reaction (RT-PCR) [28-30]. Culture methods have been developed but not commonly available.

\section{Clinical Management}

The clinical management of LF entails identification, isolation and barrier nursing of confirmed cases with observance of universal safety precautions by health personnel 31. Whereas there is specific licensed chemotherapeutic agent for LF patients, there is currently no licensed prophylactic vaccine and prevention relies chiefly on public health education and hospital training programs to prevent the nosocomial spread of the infection $[31,32]$.

Intravenous ribavirin is prescribed as soon as LF is confirmed. However oral ribavirin may be offered to suspected cases with a positive history of exposure to or contact with a LF patient. Ribavirin administered intravenously early in the course of LF has proven efficacy but the efficacy of post-exposure prophylaxis with orally administered ribavirin has not yet been confirmed by any properly conducted study [5].

Should the definitive test for LF on a suspected case already on oral ribavirin turn out to be negative, prophylaxis with Ribavirin for the contacts is discontinued. On the other hand should such persons taking oral Ribavirin based on exposure to an LF patient or suspicion develop full blown symptoms of LF, they should urgently be tested for LF by the more sensitive laboratory method, reverse-transcriptase PCR test; and chemotherapy with the intravenous form of Ribavirin started in place of oral ribavirin [33].

\section{Ribavirin}

Ribavirin is 1- $\beta$-D-ribofuranosyl-1,2,4-triazole-3carboxamide. It is a nucleotide analogue of guanosine. It exhibits broad antiviral activity against varieties of RNA and DNA viruses. It effectively suppresses the 


\section{Virology \& Immunology Journal}

proliferation of LASV in vitro but its efficacy in suppressing viremia in vivo is moderate. It causes large decline in the serum levels of aminotransferases (Alanine transferase and aspartate transferase) and significant reduction in cell damage [34].

There have been a number of mechanisms of action proposed, in peer reviewed literature, for its pharmacological actions [35]. Ribavirin is held to be an immunomodulatory agent that up-regulates some specific interferon-stimulated genes and also improves the adaptive antiviral immune response [36-39]. Ribavirin also produces a malfunctioning of the cellular enzyme IMP dehydrogenase (IMPDH) with resultant depletion of GTP (Guanosine triphosphate) and halting of viral replication [40]. Direct inhibition of viral RNA-dependent RNA polymerases, modulation of the host immune response, inhibition of viral capping enzymes, and lethal mutagenesis have also been attributed to Ribavirin [33].

The absolute oral bioavailability of ribavirin increases by $45 \%$ to $64 \%$ with high-fat diets but decreases when administered concurrently with antacids [41]. Plasma protein binding is small, it has large volume of distribution, and cerebrospinal fluid levels are up to $70 \%$ of its plasma concentration. Ribavirin elimination is mainly via the urine; so, clearance is reduced in patients with creatinine clearance less than $30 \mathrm{~mL} / \mathrm{min}$ [41]. Ribavirin greatly improves survival out come in the mouse model of Lassa fever infection when given as a combination therapy with Favipiravir, a direct-acting antiviral agent [34].

\section{Precautions}

The use of personal protective equipment including gloves, gowns, masks and goggles is effective in prevention of transmission of highly infectious viruses. Information on highly infectious diseases and education in suitable infection prevention measures should not be limited to healthcare workers, but should also include other professionals such as undertakers or cleaning staff who could potentially be affected and then in turn become sources of transmission of the virus to other people [42].

\section{Antiviral Agents and Prospects for Effective and Safe Vaccines}

Although the risk of outbreaks of viral haemorrhagic fevers including LF in various regions of the world has continued to be a significant threat to public health, and despite the enormous burden of Lassa viral haemorrhagic fever in the various affected nations there are still no approved vaccines for LF to date $[14,43]$. Development and licensing of more efficacious and safe drugs for treatment and effective vaccines to prevent LF are therefore a paramount need of the hour.

With respect to treatment, over the years, supportive clinical measures and the administration of Ribavirin have been the mainstay of therapeutic interventions for LF, however, based on successes recorded on animal models, the direct acting antiviral drug Fevipiravir appears to be a more promising treatment for LF. $[44,45]$ Monoclonal antibodies for LF treatment have also been shown to be effective when introduced early in the course of the disease in animal models (guinea pigs and nonhuman primates) of LF $[46,47]$.

Presently, number of vaccine candidates for LF is at various stages of drug development [48]. Most of these are replication-competent lassa virus vaccine modalities including the following candidate vaccine platforms: ML 29 which is a reassortment virus generated from combination of the non-pathogenic L-RNA from MOPV (Mopeia virus) and the CS_RNA from Lassa virus Josiah [49,50]; Vaccinia virus vaccine platform [51,52]; the recombinant vesicular stomatitis virus vaccine platform which has proved to be a promising vaccine development effort [53,54]; and Recombinant yellow fever vaccine platform (YFV17D) which is a recombinant vaccine employing the yellow fever $17 \mathrm{D}$ vaccine $[55,56]$. Trials of the recombinant vaccine virus platforms in animal models of LASV have yielded promising results while the recombinant VSV-LASV-GPC vaccine has been found to be safe and effective but requires further trials in human beings $[57,58,43]$.

A novel investigational vaccine named LASSARAB has also been found to be very effective in protecting rats and guinea pigs from both LF and rabies. It is an inactivated recombinant vaccine candidate consisting essentially of an attenuated rabies virus carrier with LASV genetic material inserted into it by the research teams that developed it. Preclinical trials results have been very promising with LASSARAB giving rise to antibodies against both rabies and LF in rodent models when administered with an immune response stimulating protein (GLA-SE adjuvant) [59].

\section{Conclusion}

LF has become a major public health challenge. Considering the recurring outbreaks of this virus infection in West Africa, and the attendant socioeconomic burden and loss of lives in the affected nations, development and 


\section{Virology \& Immunology Journal}

licensing of effective and safe vaccines for it have become urgent imperatives.

\section{References}

1. Shaffer JG, Grant DS, Schieffelin JS, Boisen ML, Goba A, et al. (2014) Lassa Fever in Post-Conflict Sierra Leone. PLoSNegl Trop Dis 8(3): e2748.

2. Ijarotimi IT, Ilesanmi OS, Aderinwale A, AbiodunAdewusi O, Okon IM (2018) Knowledge of Lassa fever and use of infection prevention and control facilities among health care workers during Lassa fever outbreak in Ondo State, Nigeria. Pan Afr Med J 30: 56.

3. Richmond KJ, Baglole DJ (2003) Lassa fever: epidemiology, clinical features, and social consequences. BMJ 327: 1271.

4. Hallam HJ, Hallam S, Rodriguez SE, Barrett A, Beasley D, et al. (2018) Baseline mapping of Lassa fever virology, epidemiology and vaccine research and development. NPJ vaccines 3: 11 .

5. WHO (2017) Lassa fever. Lassa fact sheet.

6. Raabe V, Koehler J (2017) Laboratory diagnosis of Lassa fever. J Clin Microbiol 55(6): 1629-1637.

7. Gibb R, Moses LM, Redding DW, Jones KE. (2017) Understanding the cryptic nature of Lassa fever in West Africa. Pathog Glob Health 111(6): 276-288.

8. Wolff S, Schultze T, Fehling SK, Mengel JP, Kann G, et al. (2016) Genome sequence of Lassa virus isolated from the first domestically acquired case in Germany. Genome Announc 4(5): e00938-16.

9. Ehlkes L, George M, Samosny G, Burckhardt F, Vogt M, et al. (2017) Management of a Lassa fever outbreak, Rhineland-Palatinate, Germany, 2016. Euro surveill 39: 16-00728.

10. Günther S, Emmerich P, Laue T, Kühle O, Asper M, et al. (2000) Imported lassa fever in Germany: molecular characterization of a new lassa virus strain. Emerg Infect Dis 6: 466-476.

11. Dahmane A, van Griensven J, Van Herp M, Van den Bergh R, Nzomukunda Y, et al. (2014) Constraints in the diagnosis and treatment of Lassa Fever and the effect on mortality in hospitalized children and women with obstetric conditions in a rural district hospital in Sierra Leone. Trans R Soc Trop Med Hyg 108(3): 126-132.
12. McCormick JB (1986) Clinical, epidemiologic, and therapeutic aspects of Lassa fever. Med Microbiol Immunol 175: 153-155.

13. Centers for Disease Control and Prevention. Lassa fever. CDC Fact sheet.

14. Monath TP, Newhouse VF, Kemp GE, Kemp GE, Setzer HW, et al. (1974) Lassa virus isolation from Mastomysnatalensis rodents during an epidemic in Sierra Leone. Science 185(4147): 263-265.

15. Warner BM, Safronetz D, Stein DR (2018) Current research for a vaccine against Lassa hemorrhagic fever virus. Drug Des Devel Ther 12: 2519-2527.

16. Yun NE, Walker DH (2012) Pathogenesis of Lassa fever. Viruses 4(10): 2031-2048.

17. Schlie K, Maisa A, Lennartz F, Ströher U, Garten W, et al. (2010) Characterization of Lassa virus glycoprotein oligomerization and influence of cholesterol on virus replication. J Virol 84(2): 983992.

18. Baize S, Kaplon J, Faure C, Pannetier D, GeorgesCourbot MC, et al. (2004) Lassa virus infection of dendritic cells and macrophages is productive but fails to activate cells. J Immunol 172(5): 2861-2869.

19. Baize S, Marianneau P, Loth $P$, Reynard S, Journeaux A, et al. (2009) Early and strong immune responses are associated with control of viral replication and recovery in lassa virus-infected cynomolgus monkeys. J Virol 83: 5890-5903.

20. Kennlyside RA, McCormick JB, Webb PA, Smith E, Elliot L, et al. (1983) Case-control study of Mastomysnatalensis and humans in Lassa virusinfected households in Sierra Leone. Am J Trop Med Hyg 32(4): 829-837.

21. McCormick JB, Webb PA, Krebs JW, Johnson KM, Smith ES (1987) A prospective study of the epidemiology and ecology of Lassa fever. J Infect Dis 155(3): 437-444.

22. Ogbu O, Ajuluchukwu E, Uneke CJ (2007) Lassa fever in West African sub-region: an overview. J Vect Borne Dis 44(1): 1-11.

23. Bausch DG, Demby AH, Coulibaly M, Kanu J, Goba A, et al. (2001) Lassa Fever in Guinea: I. Epidemiology of human disease and clinical observations. Vector Borne Zoonotic Dis 1(4): 269-281. 
24. McCormick JB, King IJ, Webb PA, Johnson KM, O'Sullivan R, et al. (1987) A case-control study of the clinical diagnosis and course of Lassa fever. J Infect Dis 155(3): 445-455.

25. Eze KC, Salami TA, Kpolugbo JU (2014) Acute abdominal pain in patients with lassa fever: radiological assessment and diagnostic challenges. Niger Med J 55(3): 195-200.

26. Branco LM, Grove JN, Boisen ML, Shaffer JG, Goba A, et al. (2011) Emerging trends in Lassa fever: redefining the role of immunoglobulin $\mathrm{M}$ and inflammation in diagnosing acute infection. Virol J 8: 478.

27. Jahrling PB, Niklasson BS, McCormick JB (1985) Early diagnosis of human Lassa fever by ELISA detection of antigen and antibody. Lancet I 325: 250-252.

28. Panning $M$, Emmerich $\mathrm{P}$, Olschläger $\mathrm{S}$, Bojenko $\mathrm{S}$, Koivogui L, et al. (2010) Laboratory diagnosis of Lassa fever, Liberia. Emerg Infect Dis 16(6): 10411043.

29. Drosten C, Göttig S, Schilling S, Asper M, Panning M, et al. (2002) Rapid detection and quantification of RNA of Ebola and Marburg viruses, Lassa virus, CrimeanCongo hemorrhagic fever virus, rift valley fever virus, dengue virus, and yellow fever virus by real-time reverse transcription-PCR. J Clin Microbiol 40: 23232330 .

30. Lunkenheimer K, Hufert FT, Schmitz H (1990) Detection of Lassa virus RNA in specimens from patients with Lassa fever by using the polymerase chain reaction. J Clin Microbiol 28(12): 2689-2692.

31. Fatiregun AA, Isere EE (2017) Epidemic preparedness and management: A guide on Lassa fever outbreak preparedness plan. Nigerian medical journal 58(1): 1-6.

32. Houlihan C, Behrens R (2017) Lassa fever. BMJ 358.

33. Bausch Daniel G, Christiane M Hadi, Sheik Humarr Khan, Juan JLL (2010) Review of the Literature and Proposed Guidelines for the Use of Oral Ribavirin as Postexposure Prophylaxis for Lassa Fever. Clinical Infectious Diseases 51(12): 1435-1441.

34. Oestereich L, Rieger T, Lüdtke A, Ruibal P, Wurr S, et al. (2016) Efficacy of Favipiravir Alone and in Combination With Ribavirin in a Lethal, Immunocompetent Mouse Model of Lassa Fever. J Infect Dis 213(6): 934-938.

\section{Virology \& Immunology Journal}

35. Lau JY, Tam RC, Liang TJ, Hong Z (2002) Mechanism of action of ribavirin in the combination treatment of chronic HCV infection. Hepatology 35(5): 1002-1009.

36. Tam RC, Pai B, Bard J, Lim C, Averett DR, et al. (1999) Ribavirin polarizes human $\mathrm{T}$ cell responses towards a Type 1 cytokine profile. J Hepatolo 30(3): 376-382.

37. Feld JJ, Hoofnagle JH (2005) Mechanism of action of interferon and ribavirin in treatment of hepatitis $\mathrm{C}$. Nature 436(7053): 967-972.

38. Feld JJ, Lutchman GA, Heller T, Hara K, Pfeiffer JK, et al. (2010) Ribavirin Improves Early Responses to PeginterferonThrough Improved Interferon Signaling. Gastroenterology 139(1): 154-62.

39. Carrillo-Bustamante P, Oestereich L, Günther S, Guedj J, Graw F, et al. (2017) Determining Ribavirin's mechanism of action against Lassa virus infection. Scientific Reports.

40. Hofmann WP, Herrmann E, Sarrazin C, Zeuzem S (2008) Ribavirin mode of action in chronic hepatitis C: From clinical use back to molecular mechanisms. Liver Int 28(10): 1332-1343.

41. Safrin S (2012) Chemotherapeutic Drugs antiviral agents, ribavirin. $12^{\text {th }}$ (Edn.), New York.

42. Lehmann C, Kochanek M, Abdulla D, Becker S, Böll B, et al. (2017) Control measures following a case of imported lassa fever from Togo, North Rhine Westphalia, Germany, 2016. Euro Surveill 22(39).

43. Geisbert TW, Jones S, Fritz EA, Shurtleff AC, Joan B, et al. (2005) Development of a new vaccine for the prevention of Lassa fever. PLoS Med 2(6): e183.

44. Rosenke K, Feldmann H, Westover JB, Hanley P, Martellaro C, et al. (2018). Use of Favipiravir to Treat Lassa Virus Infection in Macaques. Emerging Infectious Diseases 24(9): 1696-1699.

45. Raabe VN, Kann G, Ribner BS, Morales A, Varkey JB, et al. (2017) Favipiravir and Ribavirin Treatment of Epidemiologically Linked Cases of Lassa Fever. Clinical infectious diseases 65(5): 855-859.

46. Cross RW, Mire CE, Branco LM, Geisbert JB, Rowland MM, et al. (2016) Treatment of Lassa virus infection in outbred guinea pigs with first-in-class human monoclonal antibodies. Antiviral Res 133: 218-222. 


\section{Virology \& Immunology Journal}

47. Mire CE, Cross RW, Geisbert JB, Borisevich V, Agans $\mathrm{KN}$, et al. (2017) Human-monoclonal-antibody therapy protects nonhuman primates against advanced Lassa fever. Nat Med2 3(10): 1146-1149.

48. Moshkoff DA, Salvato MS, Lukashevich IS (2007) Molecular characterization of a reassortant virus derived from Lassa and Mopeia viruses. Virus Genes 34(2): 169-176.

49. Shabanov AG (1991) The isolation and characteristics of reassortants between the Lassa and Mopeiaarenaviruses. Vopr Virusol 36(2): 146-150.

50. Lukashevich IS (1992) Generation of reassortants between African arenaviruses. Virology 188(2): 600605.

51. Clegg JC, Lloyd G (1987) Vaccinia recombinant expressing Lassa-virus internal nucleocapsid protein protects guinea pigs against Lassa fever. Lancet 2(8552): 186-188.

52. Morrison HG, Bauer SP, Lange JV, Esposito JJ, McCormick JB, et al. (1989) Protection of guinea pigs from Lassa fever by vaccinia virus recombinants expressing the nucleoprotein or the envelope glycoproteins of Lassa virus. Virology 171(1):179188.

53. Safronetz D, Mire C, Rosenke K, Feldmann F, Haddock E, et al. (2015) A recombinant vesicular stomatitis virus-based Lassa fever vaccine protects guinea pigs and macaques against challenge with geographically and genetically distinct Lassa viruses. PLoS Negl Trop Dis 9(4): e0003736.

54. Marzi A, Feldmann F, Geisbert TW, Feldmann H, Safronetz D (2015) Vesicular stomatitis virus-based vaccines against Lassa and Ebola viruses. Emerg Infect Dis 21(2): 305-307.

55. Bredenbeek PJ, Molenkamp R, Spaan WJ, Deubel V, Marianneau P, et al. (2006) A recombinant Yellow Fever 17D vaccine expressing Lassa virus glycoproteins. Virology 345(2): 299-304.

56. Jiang X, Dalebout TJ, Bredenbeek PJ, Carrion R, Brasky $\mathrm{K}$, et al. (2011) Yellow fever 17D vectored vaccines expressing Lassa virus GP1 and GP2 glycoproteins provide protection against fatal disease in guinea pigs. Vaccine 29(6): 1248-1257.

57. Carrion R, Patterson JL, Johnson C, Gonzales M, Carmen R, et al. (2007) A ML29 reassortment virus protects guinea pigs against a distantly related Nigerian strain of Lassa virus and can provide sterilizing immunity. Vaccine 25(20): 4093-4102.

58. Fisher Hoch SP, Hutwagner L, Brown B, McCormick JB (2000) Effective vaccine for lassa fever. J Virol 74(5): 6777-6783.

59. Abreu-Mota T, Hagen KR, Cooper K, Jahrling PB, Tan G et al. (2018) Non-neutralizing antibodies elicited by recombinant Lassa-Rabies vaccine are critical for protection against Lassa fever. Nature Communications 9: 4223. 